\title{
ACR and SNMMI Joint Credentialing Statement for PET/MRI of the Body
}

\author{
Rathan M. Subramaniam ${ }^{1}$, Hossein Jadvar ${ }^{2}$, Patrick M. Colletti ${ }^{2}$, Alexander Guimaraes ${ }^{3}$, Rao Gullapali ${ }^{4}$, Andrei H. Iagarư \\ Jonathan McConathy ${ }^{6}$, Carolyn C. Meltzer ${ }^{7}$, Helen Nadel ${ }^{8}$, Richard B. Noto ${ }^{9}$, Alan B. Packard ${ }^{10}$, Eric M. Rohren ${ }^{11}$, \\ and M. Elizabeth Oates ${ }^{12}$ \\ ${ }^{1} U T$ Southwestern Medical Center, Dallas, Texas; ${ }^{2}$ University of Southern California, Los Angeles, California; ${ }^{3}$ Oregon Health and \\ Science University, Portland, Oregon; ${ }^{4}$ University of Maryland, Baltimore, Maryland; ${ }^{5}$ Stanford University, Stanford, California; \\ ${ }^{6}$ University of Alabama, Birmingham, Alabama; ${ }^{7}$ Emory University, Atlanta, Georgia; ${ }^{8}$ University of British Columbia, Vancouver, \\ British Columbia; ${ }^{9}$ Brown University, Providence, Rhode Island; ${ }^{10}$ Boston Children's Hospital, Boston, Maryland; ${ }^{11}$ Baylor College \\ of Medicine, Houston, Texas; and ${ }^{2}$ University of Kentucky, Lexington, Kentucky.
}

$\mathbf{F}$ ounded in 1951, the Joint Commission, formally known as the Joint Commission on Accreditation of Healthcare Organizations and, previous to that, the Joint Commission on Accreditation of Hospitals, is a U.S.-based nonprofit organization that accredits more than 20,000 health-care organizations and programs in the United States. The Joint Commission requires that there be a credentialing system for delineating and granting privileges to every hospital physician. The Joint Commission does not specify the qualifications. Privileges are generally practice-specific and are not usually transferable from hospital to hospital. The granting of clinical privileges cannot and should not depend on a single criterion such as board certification or membership in a particular specialty society; other options, such as documented evidence of requisite training, relevant experience, judgment skills, and demonstrated current competence, should be available. It is the final responsibility of the hospital medical staff and hospital governing board to ensure that a physician meets a reasonable standard of competency.

PET/MRI is an emerging complex hybrid imaging modality recently introduced into clinical practice. In June 2013, the American College of Radiology (ACR) and the Society of Nuclear Medicine and Molecular Imaging (SNMMI) charged a joint task force with developing a credentialing statement for physicians responsible for the oversight and interpretation of PET/MRI examinations. The task force has prepared this joint statement related to PET/MRI of the body (head and neck, chest, abdomen, pelvis, skeleton, and extremities) as the second in a planned series of credentialing documents covering all organ systems and clinical applications. The first, on PET/MRI of the brain, was published in 2015 (1).

This joint statement is intended to guide credentialing bodies that privilege physicians to oversee the performance of PET/MRI, and participate in the interpretation of PET/MR images, in adult and pediatric patients in the United States.

Received Mar. 20, 2017; accepted Mar. 20, 2017.

For correspondence or reprints contact: Rathan M. Subramaniam, Department of Radiology, UT Southwestern Medical Center, 5323 Harry Hines Blvd., Dallas, TX 75390-8896.

E-mail: rathan.subramaniam@utsouthwestern.edu

Published online May 4, 2017.

COPYRIGHT @ 2017 by the Society of Nuclear Medicine and Molecular Imaging. DOI: 10.2967/jnumed.117.193524

\section{DEFINITIONS}

For the purposes of this statement, the following definitions apply:

Body: Head and neck, chest, abdomen, pelvis, skeleton, and extremities.

MRI: A medical imaging technology that uses high-strength magnetic fields to create high-contrast tomographic images. MRI techniques primarily delineate anatomy, but special MRI sequences such as functional MRI, MR spectroscopy, and perfusion- and diffusion-weighted MRI provide functional information.

PET: A medical imaging technology that uses positron-emitting radiopharmaceuticals. The PET scanner detects high-energy annihilation photon pairs and extrapolates the location of the original positron-emitting atoms to create tomographic images of their biodistribution within the body.

PET/MRI: A complex hybrid medical imaging technology that incorporates PET and MRI into a single device. Such an imaging system allows either sequential acquisition (i.e., tandem back-to-back design) or simultaneous acquisition (i.e., a PET insert in an MRI gantry or an integrated PET/MRI design). In either hybrid system, the goal is to combine PET and MR image data for exact coregistration.

Radiopharmaceutical: A radioactive compound administered to patients for use in diagnosis and therapy.

\section{APPLICATIONS FOR BODY PET/MRI}

The following are examples of potential clinical or research applications for PET/MRI of the body (2-6): neoplastic conditions, masses or masslike conditions of the head and neck, the gastrointestinal system (esophagus, stomach, small and large bowel, liver, gallbladder, pancreas, and adrenal glands), the genitourinary system (kidney, urinary bladder, gonads, uterus, cervix, and prostate gland), and the female breast. With certain limitations, the following are additional potential applications: the lungs; the skin (e.g., melanoma); the musculoskeletal system (e.g., sarcoma); the hematopoietic (bone marrow and spleen) and lymphatic (e.g., lymphoma) systems; inflammatory, infectious, and autoimmune disorders; and, in children, neoplastic conditions 
TABLE 1

Initial and Continuing Competency Criteria for Credentialing Physicians to Independently Practice Body PET/MRI*

\begin{tabular}{|c|c|c|c|c|}
\hline \multirow[b]{2}{*}{ Certification type } & \multicolumn{2}{|c|}{ Initial criteria } & \multicolumn{2}{|c|}{ Continuing criteria } \\
\hline & $\begin{array}{l}\text { Supervised } \\
\text { interpretations in } \\
\text { past } 36 \mathrm{mo}\end{array}$ & $\begin{array}{l}\text { Didactic education in past } \\
\qquad 36 \mathrm{mo}\end{array}$ & $\begin{array}{l}\text { Supervised } \\
\text { interpretations in } \\
\text { past } 36 \mathrm{mo}\end{array}$ & $\begin{array}{c}\text { Didactic education in } \\
\text { past } 36 \text { mo }\end{array}$ \\
\hline $\begin{array}{l}\text { ABR-DR, ABR-DR-NR, ABNM, } \\
\text { AOBR, RCPSC, or Collège } \\
\text { des Médecins du Québec } \\
\text { certification, or board } \\
\text { eligibility within } 2 \text { y of } \\
\text { completing residency or } \\
\text { fellowship }\end{array}$ & $\begin{array}{l}150 \text { body PET/CT; } \\
300 \text { body MRI }\end{array}$ & PET/CT: 20 h; MRI: 100 h & $\begin{array}{l}\text { Direct participation in } \\
200 \text { body PET/ } \\
\text { MRI minimum, or } \\
200 \text { body PET/CT } \\
\text { plus } 200 \text { body MRI }\end{array}$ & $\begin{array}{l}6 \text { h } \mathrm{CME} \text { minimum in } \\
\text { body } \mathrm{PET} / \mathrm{MRI} \\
\mathrm{PET} / \mathrm{CT} \text {, or } \mathrm{MRI}\end{array}$ \\
\hline $\begin{array}{l}\text { DR or NM residency accredited } \\
\text { by ACGME, RCPSC, Collège } \\
\text { des Médecins du Québec, } \\
\text { or AOA without board } \\
\text { certification and more than } \\
2 \text { y since completing } \\
\text { residency or fellowship }\end{array}$ & $\begin{array}{l}250 \text { body PET/CT; } \\
500 \text { body MR }\end{array}$ & PET/CT: 50 h; MRI: 250 h & $\begin{array}{l}\text { Direct participation in } \\
300 \text { body PET/ } \\
\text { MRI minimum, or } \\
300 \text { body PET/CT } \\
\text { plus } 300 \text { body MRI }\end{array}$ & $\begin{array}{l}15 \text { h CME minimum } \\
\text { in body PET/MRI, } \\
\text { PET/CT, or MRI }\end{array}$ \\
\hline $\begin{array}{l}\text { ABMS or Canadian-equivalent } \\
\text { board certification in another } \\
\text { medical specialty }\end{array}$ & $\begin{array}{l}500 \text { body PET/CT; } \\
750 \text { body MRI }\end{array}$ & $\begin{array}{l}\text { PET/CT: } 500 \mathrm{~h}+200 \mathrm{~h} \text { in } \\
\text { radiation physics, } \\
\text { instrumentation, } \\
\text { radiochemistry, } \\
\text { radiopharmacology, radiation } \\
\text { dosimetry, radiation biology, } \\
\text { or radiation safety and in } \\
\text { protection, quality control, or } \\
\text { artifacts }+1,000 \mathrm{~h} \text { in clinical } \\
\mathrm{NM} \text {, including dosages, } \\
\text { image evaluation, correlation } \\
\text { with other imaging, and } \\
\text { interpretation; MR imaging: } \\
500 \mathrm{~h}+200 \mathrm{~h} \text { in MRI physics, } \\
\text { instrumentation, chemistry, } \\
\text { contrast agents and use, } \\
\text { imaging techniques, MR } \\
\text { safety, quality control, } \\
\text { artifacts, clinical application, } \\
\text { or interpretation }\end{array}$ & $\begin{array}{l}\text { Direct participation in } \\
500 \text { body PET/ } \\
\text { MRI minimum, or } \\
500 \text { body PET/CT } \\
\text { plus } 500 \text { body MRI }\end{array}$ & $\begin{array}{l}30 \text { h CME minimum } \\
\text { in body PET/MRI, } \\
\text { PET/CT, or MRI }\end{array}$ \\
\hline
\end{tabular}

*The term body refers to head and neck, chest, abdomen, pelvis, skeleton, and extremities.

ABR-DR = American Board of Radiology-Diagnostic Radiology; ABR-DR-NR = American Board of Radiology-Diagnostic Radiology + Nuclear Radiology; ABNM = American Board of Nuclear Medicine; AOBR = American Osteopathic Board of Radiology; RCPSC = Royal College of Physicians and Surgeons of Canada; DR = diagnostic radiology; NM = nuclear medicine; $\mathrm{ACGME}=\mathrm{Accreditation}$ Council for Graduate Medical Education; AOA = American Osteopathic Association; ABMS = American Board of Medical Specialties; CME = continuing medical education.

and other relevant indications, which may include Langerhans cell histiocytosis, neurofibromatosis, and fever of unknown origin. In certain clinical conditions, PET radiopharmaceuticals other than ${ }^{18}$ F-FDG may be most relevant.

\section{RESPONSIBILITIES OF PHYSICIANS}

A physician must be responsible for all aspects of the body PET/ MRI examination, such as reviewing the indication for the examination, prescribing the PET radiopharmaceutical and its dose, specifying the MRI pulse sequence to be performed, prescribing the use and dose of MRI contrast agent, confirming that the quality of the images is appropriate for interpretation, interpreting the images, generating the final report, and ensuring patient and personnel safety. A prescriber of radiopharmaceuticals must either be or work under a U.S. Nuclear Regulatory Commission-authorized user of radioactive materials and comply with state regulations, or hold the equivalent Canadian authorization.

In their practice with regard to supervision and interpretation of body PET/MRI, physicians may best participate according to their special interests and qualifications in nuclear medicine and molecular imaging, diagnostic radiology, or related practice paradigms. It is recognized that variations in the local regulatory requirements for practices and the local qualifications for individual physicians may of necessity dictate site-specific practice patterns. For example, in certain clinical settings, it may be beneficial for two physicians to interpret body PET/MRI examinations together, with one interpreting primarily the PET component and other interpreting primarily the MRI component. 
Nevertheless, the interpreters should meet the credentialing criteria for the modality for which they are providing a primary interpretation. The two physicians must reach consensus regarding the final interpretation of the combined PET/MRI findings in order to issue a joint PET/MRI report (with one billing physician of record) or two separate correlative PET and MRI reports.

Simple numeric criteria are not an optimal measure of competency. Documentation of competency by the use of objective, outcome-based tools related to clinical experience is preferable. The criteria detailed in Table 1 may be used for guidance.

The rigorous recommendations for PET/MRI practice set forth in this document have been developed in consideration of the complex nature of this emerging hybrid modality and with reference to published practice parameters, procedure standards, and credentialing statements (7-9).

The practice of PET/MRI requires a solid knowledge base of PET techniques and MRI techniques. Although the ultimate goal is mastery of simultaneously acquired body PET/MRI examinations, the physician's education, training, and experience should encompass body PET (or PET/CT) and body MRI. Fundamentals include familiarity with technical parameters (protocols, contrast agents, sequences, and processing) as well as biologic and clinical parameters (anatomy, physiology, normal variants, and disease states).

The recommendations set forth include, first, a first-hand review and supervised interpretation of hybrid PET/MRI or separately acquired PET (or PET/CT) and MRI examinations of the body and, second, didactic educational hours in the basic science and clinical applications of each modality.

\section{QUALIFICATIONS OF PHYSICIANS RESPONSIBLE FOR BODY PET/MRI—INITIAL COMPETENCY}

All physicians assuming responsibility for independent practice of body PET/MRI should meet the criteria for at least one of the initial competency categories outlined in Table 1.

\section{Clinical Experience/Supervised Interpretations}

In each modality, cases must include broad representation of types of examinations, available radiopharmaceuticals, contrast agents, and indications encountered in clinical practice. Cases presented in specifically designed society- or organizationapproved case-based conferences or courses, live or online, are acceptable. Documented cases with direct participation during residency or fellowship may be counted. Of note, hybrid body PET/MRI cases may be counted in each appropriate category (i.e., they may be counted twice) to fulfill the recommendation.

\section{Didactic Education Hours}

Didactic education should supplement case-based conferences used to achieve the number of supervised interpretations and should include PET physics plus MRI physics, body PET radiopharmaceuticals plus MRI contrast agents, safe handling of radioactive materials plus MRI safety, and PET plus MRI protocols (sequences). Hours spent during residency or fellowship are acceptable.

\section{QUALIFICATIONS OF PHYSICIANS RESPONSIBLE FOR BODY PET/MRI-CONTINUING COMPETENCY}

All physicians assuming responsibility for independent practice of body PET/MRI should meet the criteria for at least one of the continuing competency categories outlined in Table 1

\section{Clinical Experience/Supervised Interpretations}

Cases must comprise a broad representation of types of examinations, available radiopharmaceuticals, contrast agents, and indications encountered in clinical practice, including cases presented in specifically designed society- or organization-approved case-based conferences. Direct participation in clinical cases should include involvement in all aspects of examination from protocoling through interpretation; effective participation cannot be achieved by more than 3 individuals per case. Objective documentation of direct participation should be kept by each physician.

\section{Didactic Education Hours}

Didactic education should include at least $50 \%$ of the required hours in body PET/MRI, with the remainder in body PET/CT or body MRI, or at least $50 \%$ of required hours in body PET/CT and at least $50 \%$ in body MRI.

\section{APPROVAL}

This credentialing statement was approved by the ACR board of chancellors and by the SNMMI board of directors in January 2017.

\section{JOINT TASK FORCE PARTICIPANTS}

The ACR participants include Rathan M. Subramaniam (cochair), Alexander Guimaraes, Rao Gullapali, Jonathan McConathy, Carolyn C. Meltzer, and M. Elizabeth Oates. The SNMMI participants include Hossein Jadvar (cochair), Patrick M. Colletti, Andrei H. Iagaru, Helen Nadel, Richard B. Noto, Alan B. Packard, and Eric M. Rohren.

\section{REFERENCES}

1. Jadvar H, Subramaniam R, Berman CG, et al. American College of Radiology and Society of Nuclear Medicine and Molecular Imaging joint credentialing statement for PET/MR imaging: brain. J Nucl Med. 2015;56:642-645.

2. Fraum TJ, Fowler KJ, McConathy J. PET/MRI: emerging clinical applications in oncology. Acad Radiol. 2016;23:220-236.

3. Buchbender C, Heusner TA, Lauenstein TC, et al. Oncologic PET/MRI, part 2: bone tumors, soft tissue tumors, melanoma, and lymphoma. J Nucl Med. 2012;53:1244-1252.

4. Flechsig P, Mehndiratta A, Haberkorn U, et al. PET/MRI and PET/CT in lung lesions and thoracic malignancies. Semin Nucl Med. 2015;45:268-281.

5. Pugmire BS, Guimaraes AR, Lim R, et al. Simultaneous whole body ${ }^{18} \mathrm{~F}$-fluorodeoxyglucose positron emission tomography magnetic resonance imaging for evaluation of pediatric cancer: preliminary experience and comparison with ${ }^{18} \mathrm{~F}$-fluorodeoxyglucose positron emission tomography computed tomography. World J Radiol. 2016;8:322-330.

6. Pampaloni MH, Nardo L. PET/MRI radiotracer beyond ${ }^{18}$ F-FDG. PET Clin. 2014;9:345-349.

7. ACR practice parameter for performing and interpreting magnetic resonance imaging (MRI). American College of Radiology website. http://www.acr.org/ /media/ EB54F56780AC4C6994B77078AA1D6612.pdf. Published 1992. Last amended 2014. Accessed April 11, 2017.

8. ACR-SPR practice parameter for performing FDG-PET/CT in oncology. American College of Radiology website. http://www.acr.org/ /media/71B746780F934F6D8A1BA5CCA5167EDB.pdf. Published 2007. Last revised 2016. Accessed April 2017.

9. Conjoint statement of the SNM and the ACNP on credentialing and delineation of privileges for body PET. $J$ Nucl Med. 2006;47:1559-1560. 